PÁGINA DEL EDITOR

\title{
Publicación científica en estudiantes de medicina: Un reto de desarrollo
}

\author{
Hazel Vivian Soliz Alconz', Zenia Claros Coca²
}

$\mathrm{L}$ a publicación es el último paso en el proceso investigativo y la cantidad y calidad de las mismas constituye un indicador de medición del desarrollo de las universidades y el país. Bolivia cuenta con una participación escasa en lo que corresponde a los aportes investigativos siendo considerados "pequeños productores" aportando 0,10\% según un estudio realizado en Cuba, en el cual se determinó la procedencia de la producción científica en salud en la base de datos PubMed durante el período de 1999-2008 en Iberoamérica, en dicho estudio Brasil es responsable de más del 50\% del total de la producción científica en salud, junto a México y Argentina que en conjunto producen más del 80\%, recibiendo la denominación de "grandes productores". El grupo de los "productores medianos" cuyos aportes se sitúan entre el 1 y el 6\% son Chile, Colombia, Venezuela, Cuba, Puerto Rico y Uruguay ${ }^{1}$.

Si bien Bolivia se encuentra entre los escaños más bajos surge también la disyuntiva de si la investigación científica migra al extranjero y no es publicada en revistas nacionales, como sugiere un estudio realizado de artículos originales sobre Perú, Colombia, Venezuela, Bolivia o Ecuador, publicados en Medline entre 1993 y 1994, se encontraron 627 artículos publicados: 70 en revistas de los 5 países, 37 en otras revistas latinoamericanas y 510 en revistas americanas o europeas ${ }^{2}$.

Las universidades son casas formadoras de grandes profesionales y a la par también deben ser formadoras de grandes investigadores; durante los seis ańos en el transcurso de la carrera de medicina, los mismas constituyen un elemento vital a la hora de instruir y guiar por el camino de la ciencia, culminando en la publicación, existiendo revistas medico estudiantiles, como la Revista Científica Ciencia Médica, que trabaja para lograr dicho propósito. Pero la situación actual es muy diferente a la esperada, ya que se ha notado un descenso de la producción científica acompañado de un escaso interés, resaltando entre la principal causa la insuficiente cultura de publicación ${ }^{3}$.

Otro punto importante a destacar es la cuantificación de la actividad y producción científica en las Sociedades Científicas de Estudiantes de Medicina, la cuál a pesar de los esfuerzos y actividades desarrolladas aún no han logrado satisfacer dicha expectativa.

Es por ello que las revistas científicas de estudiantes de pre-grado cumplen un papel importante en el desarrollo de la investigación científica, siendo parte así de la contribución y producción en Bolivia que no debe ser subestimada ya que brindan la oportunidad para involucrar a los estudiantes en un nivel más personal de comprensión ${ }^{4}$.

Es parte de nuestro propósito continuar difundiendo y promover la investigación científica en estudiantes de medicina además de mejorar constantemente la calidad científica, frente a los muchos desafíos que esto implica, todo ello es fundamental para lograr desarrollar el potencial científico esperado, mediante el pensamiento crítico y el desarrollo de futuros médicos científicos.

\footnotetext{
${ }^{1}$ Hazel Vivian Soliz Alconz

Editora en jefe - Revista Científica Ciencia Médica, Sociedad Científica de Estudiantes de Medicina, Auxiliar del Departamento de Educación Médica Continua y Planificación, Facultad de Medicina Universidad Mayor de San Simón, Cochabamba - Bolivia.

Correspondencia a:

vsolizalconz@gmail.com
}

${ }^{2}$ Zenia Claros Coca

Editora asociada —Revista Científica Ciencia Médica, Facultad de Medicina Universidad Mayor de San Simón, Cochabamba - Bolivia. 


\section{EDITORIAL}

\section{Referencias:}

1. 1. Cañedo A., Cuba, Iberoamérica y la producción científica en salud en la base de datos PubMed en el período 1999-2008. ACIMED 2009; 20(1): Disponible en: http://scielo.sld.cu/scielo.php?script=sci_arttext\&pid $=$ S1024-94352009000700002.

2. Pardo E., Obstáculos al desarrollo de investigación y publicación en salud en Bolivia: el rol de la Gaceta Médica Boliviana. Gac Med Bol 2012; 35 (2): 1. Disponible en: http://www.scielo.org.bo/scielo.php?pid=S101229662012000200001 escript $=$ sci_arttext.
3. Oróstegui D., Cabrera I., Angulo Y., Mayta-Tristán P., Rodriguez-Morales A., Encuentros internacionales de revistas científicas estudiantiles de las ciencias de la salud en Latinoamérica, 1998-2008. Rev Panam Salud Publica 2009; 25(5). Disponible en: http://www.scielosp.org/scielo. php?script=sci_arttexte ${ }^{\prime}$ pid $=S 1020-49892009000500014$.

4. Steven L., Student Journals: Facilitating Medical Student Research and Physician-Scientist Development. Mcgill J Med. 2006; 9(2): 82-83. Disponible en: http:// www.ncbi.nlm.nih.gov/pmc/articles/PMC2323521/.

\section{Lista de comprobación para el envío de manuscritos}

$\square$ Este trabajo (o partes importantes de él) es inédito y no está siendo considerado en otras revistas.

$\square$ Se indican números telefónicos, dirección y el correo electrónico del autor responsable.

$\square$ El texto sigue el formato de la Revista Científica Ciencia Médica, de la plantilla DOT de Microsoft Word.

$\square$ El título es conciso v está en idioma espafiol e inglés

$\square$ Tiene un titulo corto que no excede de 72 carácteres.

$\square$ El trabajo no excede de 3000 palabras (originales), 3500 (revisión), 2500 (casos clínicos) y 750 (cartas al editor)

$\square$ Incluye un resumen estructurado de hasta 250 palabras (originales). Resumen no estructurado de 150 palabras (revisión y casos clínicos)

$\square$ Las citas bibliográficas están correctamente citadas, y en su mayoría proceden de revistas o libros.

$\square$ Se envian las copias indicadas en las instrucciones para el autor en formato carta más el CD con el archivo digital del manuscrito.

\section{Información para el autor: Búsqueda de palabras MeSH}

1. Ingresa a: http://www.nlm.nih.gov/mash/Mbrowser.html

2. Introducir la palabra clave que se quiera comprobar

3. Seleccionar "Descriptor"

4. Se indicará si existe o no la palabra clave seleccionada 